\title{
Does regular quality control improve the quality of surgery in Slovenian breast cancer screening program?
}

\author{
Andraz Perhavec ${ }^{1,2}$, Sara Milicevic ${ }^{1}$, Barbara Peric ${ }^{1,2}$, Janez Zgajnar ${ }^{1,2}$ \\ ${ }^{1}$ Department of Surgical Oncology, Institute of Oncology Ljubljana, Ljubljana, Slovenia \\ ${ }^{2}$ Faculty of Medicine, University of Ljubljana, Ljubljana, Slovenia
}

Radiol Oncol 2020; 54(4): 488-494.

Received 4 April 2020

Accepted 26 April 2020

Correspondence to: Prof. Janez Žgajnar, M.D., Ph.D., Department of Surgical Oncology, Institute of Oncology Ljubljana, Zaloska 2, SI-1000 Ljubljana, Slovenia. E-mail: e-mail: jzgajnar@onko-i.si

Disclosure: No potential conflicts of interest were disclosed.

Background. The aim of our study was to evaluate the quality of surgery of Slovenian breast cancer screening program (DORA) using the requested EU standards. Furthermore, we investigated whether regular quality control over the 3-year period improved the quality of surgical management.

Patients and methods. Patients who required surgical management within DORA between January 1st, 2016 and December 31st, 2018 were included in the retrospective study. Quality indicators (QIs) were adjusted mainly according to European Society of Breast Cancer Specialists (EUSOMA) and European Breast Cancer Network (EBCN) recommendations. Five Qls for therapeutic and two for diagnostic surgeries were selected. Additionally, variability in achieving the requested Qls among surgeons was analysed.

Results. Between 2016 and 2018, 14 surgeons performed 1421 breast procedures in 1398 women. There were 1197 therapeutical (for proven breast cancer) and 224 diagnostic surgical interventions respectively. Overall, the minimal standard was met in two Qls for therapeutic and none for diagnostic procedures. A statistically significant improvement in three QIs for therapeutic and in one QI for diagnostic procedures was observed however, indicating that regular quality control improves the quality of surgery. A high variability in achieving the requested Qls was observed among surgeons, which remained high throughout the study period.

Conclusions. Adherence to all selected surgical QIs in patients from screening program is difficult to achieve, especially to those specifically defined for screen-detected lesions. Regular quality control may improve results over time. Reducing the number of surgeons dedicated to breast pathology may reduce variability of management inside the institution.

Key words: breast surgery; mammography screening program; quality control

\section{Introduction}

Breast cancer is the most common female cancer with an estimated incidence of 523,000 cases in Europe in 2018 and the third leading common cause of death from cancer $(138,000$ cases per year). ${ }^{1}$ A 5 -year survival rate in women with breast cancer ranges from $25.1 \%$ to $95.7 \%$ and depends mainly on the stage of the disease at the time of diagnosis. ${ }^{2}$ Screening programs are efficient in early detection of cancer and lead to a better prognosis and less intensive treatment. ${ }^{3,4}$
As the management of early breast cancer is complex, the optimal outcomes are ensured in the specialized multidisciplinary breast cancer centres. ${ }^{5}$ Comprehensive quality assurance is of great importance for maintaining the appropriate balance between benefits and harms. ${ }^{3}$ European Society of Breast Cancer Specialists (EUSOMA) and European Breast Cancer Network (EBCN) provided a set of quality indicators (QIs) in order to establish minimum standard of care and to improve the quality of care, patient satisfaction and outcome. QIs also allow standardised quality of care evaluation. ${ }^{5-7}$ 
Slovenian breast cancer screening program, called DORA, is a national population-based organized screening program inviting women aged 50-69 to biannual mammography and it is aimed to detect breast cancer in asymptomatic women in early stages. Quality of surgery and the impact of regular quality control on improvement of QIs within screening program is not known. In 2016, we defined and regularly monitored a set of surgical QIs mainly from EUSOMA and EBCN for women that undergo surgical procedure for a suspicious or malignant lesion detected in Slovenian Breast Cancer screening Program.

The aim of our study was to evaluate the quality of surgical treatment of patients from the DORA program and to investigate whether the surgical approach fulfils the requested EU standards. Furthermore, we investigated whether regular quality control over the 3-year period improved the quality of surgical management.

\section{Patients and methods}

A retrospective study of women who required surgical management within Slovenian Breast Cancer screening Programme between January 1 1st, 2016 and December 31 $1^{\text {st }}, 2018$ was performed. The data were prospectively collected from the National screening programme registry and missing data supplemented by reviewing patient's records.

Slovenian National screening program DORA, with centrally organized invitation system, provides screening mammography every two years for women aged from 50 to 69 with residence in Slovenia. The programme was initiated in April 2008. The average participation rate in the years between 2008 and 2018 was $73 \%$. Between 2016 and $2018,216,717$ women were screened in the DORA programme. A total of $1352(0.6 \%)$ breast cancers were detected during that time. ${ }^{8}$

For the purpose of this study, patients were divided into two groups: the group in which breast cancer was preoperatively histologically or cytologically confirmed (B5 or C5 lesions) and the group in which diagnostic surgical procedure was performed due to lesions of uncertain malignant potential.

A decision on management of screen-detected breast cancer was always made within multidisciplinary tumour board. Thus, this QI was not monitored, as it was not expected to change over time. Since all patients were operated at the same institution (Institute of oncology Ljubljana), the same rationale approaches were used.
All but one QIs have been chosen according to EUSOMA recommendations from 2010 and EBCN recommendations from 2006, ${ }^{6,7}$ We did not include all QIs as we do not routinely collect all the required data. Furthermore, we tried to avoid becoming overwhelmed with too many indicators.

QIs that have been defined and regularly monitored in patients in which breast cancer was preoperatively histologically or cytologically confirmed are:

(1) median waiting time (in days) from multidisciplinary tumour board to surgery and proportion of patients who waited less than 15 working days from multidisciplinary tumour board to surgery: both EUSOMA and EBCN consider waiting time as a QI; since in our study only patients with screen detected lesions were included, we decided to choose more strict EBCN recommendation;

(2) proportion of patients (invasive and noninvasive cancers) who received a single (breast) operation for the primary tumour (excluding reconstruction): EUSOMA recommendation considers invasive and noninvasive cancers separately and the recommendation is stricter for invasive cancers $(80 \%)$ compared to noninvasive cancers $(70 \%)$; we decided to combine invasive and noninvasive cancers into one QI with stricter criteria to provide more robust numbers and to avoid becoming overwhelmed with too many rather similar QIs;

(3) proportion of patients with invasive breast cancer not greater than $3 \mathrm{~cm}$ (total pathological size, including DCIS component) who underwent breast conserving treatment (BCT): EUSOMA QI;

(4) proportion of patients with invasive cancer and axillary clearance performed with at least 10 lymph nodes (LN) examined: EUSOMA QI;

(5) mean weight of the excised specimen and the proportion of specimens from the breast with weight less than $80 \mathrm{~g}$ when breast conserving surgery was performed: this is neither the EUSOMA nor the EBCN QI. We decided to include it as a surrogate of expected cosmetic result. The average specimen from breast conserving surgery should weigh between 20 and $40 \mathrm{~g}$ and as a general rule, $80 \mathrm{~g}$ of breast tissue is the maximum weight that can be removed from a medium-sized breast without resulting in deformity. ${ }^{9}$

QIs that have been regularly monitored in patients in which diagnostic surgical procedure was performed due to lesions of uncertain malignant potential are: 
(1) median waiting time (in days) from multidisciplinary tumour board to surgery and proportion of patients who waited less than 15 working days from multidisciplinary tumour board to surgery: EBCN QI;

(2) mean weight of the excised specimen and the proportion of specimens with weight less than 30 g: EBCN QI.

Patients who received neoadjuvant chemotherapy were excluded from calculations of median waiting time.

All selected QIs have been regularly monitored each year, starting in 2016.

All statistical analyses were performed using SPSS for Windows, version 22.0. Data were summarized using frequencies and percentages for categorical variables and median or mean for continuous variables. Chi square test was used to compare categorical variables and Mann-Whitney test or ANOVA for continuous variables. P-values $\leq 0.05$ were considered statistically significant.

This study was conducted according to the rules of the Ethical Committee of the Institute of oncology Ljubljana.

\section{Results}

Between 2016 and 2018, 14 surgeons performed 1421 breast procedures in 1398 women from breast cancer screening program DORA. There were 1197 procedures therapeutic because of histologically or cytologically proven invasive or in situ breast cancer and 224 procedures were diagnostic because of lesions of uncertain malignant potential.
To determine whether our surgical approach reaches the requested EU standards, quality of care was evaluated by predefined QIs.

Pathologic characteristics of patients that underwent therapeutic surgical procedures split by the year of treatment are shown in Table 1. Quality indicators of therapeutic surgical procedures split by the year of surgery are shown in Table 2 .

Pathologic characteristics of patients that underwent diagnostic surgical procedures split by the year of surgery are shown in Table 3. Quality indicators of diagnostic surgical procedures split by the year of surgery are shown in Table 4 .

Nineteen out of $224(8.5 \%)$ patients needed reoperation after diagnostic breast surgical procedure; 5/224 (2.2\%) re-excision, 4/224 (1.8\%) mastectomy, $2 / 224(0.9 \%)$ re-excision followed by mastectomy and 8/224 (3.6\%) only sentinel lymph node biopsy.

There were 1421 breast procedures performed by 14 surgeons. The variability among surgeons in 3 years period is shown in Table 5 .

\section{Discussion}

Regularly reporting and analysing outcome data is important in order to allow centres to ensure patients with breast cancer the optimal management and to recognise the particular areas, where the improvements are required. Namely, focusing on QIs shows higher compliance to recommended treatment and better outcome. ${ }^{10-14}$ Furthermore, by providing outcome data, the new scientific knowledge is incorporated and minimum standards are upgraded. ${ }^{5}$

TABLE 1. Characteristics of therapeutic procedures performed between 2016 and 2018

\begin{tabular}{|c|c|c|c|c|c|}
\hline \multirow{2}{*}{ No. of procedures } & All & 2016 & 2017 & 2018 & \multirow{2}{*}{ p-value } \\
\hline & 1197 & 296 & 417 & 484 & \\
\hline $\begin{array}{l}\text { Procedure type in breast } \\
\text { BCT } \\
\text { mastectomies }\end{array}$ & $\begin{array}{l}927(77.4 \%) \\
270(22.6 \%)\end{array}$ & $\begin{array}{l}218(73.6 \%) \\
78(26.4 \%)\end{array}$ & $\begin{array}{l}312(74.8 \%) \\
105(25.2 \%)\end{array}$ & $\begin{array}{l}397(82.0 \%) \\
87(18.0 \%)\end{array}$ & 0.007 \\
\hline $\begin{array}{l}\text { Procedure type in axilla: } \\
\text { none } \\
\text { SNB } \\
\text { ALND } \\
\text { SNB + ALND }\end{array}$ & $\begin{array}{c}202(16.9 \%) \\
858(71.7 \%) \\
87(7.3 \%) \\
50(4.2)\end{array}$ & $\begin{array}{l}34(11.5 \%) \\
211(71.3 \%) \\
35(11.8 \%) \\
16(5.4 \%)\end{array}$ & $\begin{array}{c}72(17.3 \%) \\
304(72.9 \%) \\
25(6.0 \%) \\
16(3.8 \%)\end{array}$ & $\begin{array}{c}96(19.8 \%) \\
343(70.9 \%) \\
27(5.6 \%) \\
18(3.7 \%)\end{array}$ & 0.002 \\
\hline $\begin{array}{l}\text { Histologic tumour type } \\
\text { Benign } \\
\text { In situ } \\
\text { Microinvasive carcinoma } \\
\text { Invasive carcinoma } \\
\text { Other }\end{array}$ & $\begin{aligned} 64 & (5.3 \%) \\
214 & (17.9 \%) \\
19 & (1.6 \%) \\
899 & (75.1 \%) \\
1 & (0.1 \%)\end{aligned}$ & $\begin{array}{c}6(2.0 \%) \\
50(16.9 \%) \\
2(0.7 \%) \\
238(80.4 \%) \\
0(0.0 \%)\end{array}$ & $\begin{array}{c}19(4.6 \%) \\
84(20.1 \%) \\
12(2.9 \%) \\
302(72.4 \%) \\
0(0.0 \%)\end{array}$ & $\begin{array}{c}39(8.1 \%) \\
80(16.5 \%) \\
5(1.0 \%) \\
359(74.2 \%) \\
1(0.2 \%)\end{array}$ & 0.004 \\
\hline $\begin{array}{l}\text { Mean tumour diameter } \pm \\
\text { S.D. }(\mathrm{mm})\end{array}$ & $17.8 \pm 13.3$ & $18.9 \pm 14.6$ & $18.2 \pm 13.6$ & $16.8 \pm 12.0$ & 0.127 \\
\hline
\end{tabular}

ALND = axillary lymph node dissection; $B C T=$ breast conserving treatment; S.D. = standard deviation; SNB = sentinel node biopsy 
TABLE 2. Quality indicators of therapeutic surgical procedures split by the year of treatment

\begin{tabular}{|c|c|c|c|c|c|c|}
\hline & Recommendation: & All & 2016 & 2017 & 2018 & $p$-value \\
\hline \multicolumn{7}{|l|}{ 1. QI: waiting time } \\
\hline $\begin{array}{l}\text { Median (days) } \\
\text { Proportion of patients with } \\
\text { waiting time less than } 15 \\
\text { working days }\end{array}$ & $\begin{array}{c}\text { Not more than } 15 \text { working } \\
\text { days } \geq 90 \%\end{array}$ & $\begin{array}{c}33 \\
4.2 \%\end{array}$ & $\begin{array}{c}38 \\
1.7 \%\end{array}$ & $\begin{array}{c}34 \\
2.9 \%\end{array}$ & $\begin{array}{c}28 \\
6.9 \%\end{array}$ & $<0.001$ \\
\hline $\begin{array}{l}\text { 2. Ql: proportion of patients } \\
\text { (invasive and noninvasive } \\
\text { cancers) who received a } \\
\text { single (breast) operation for } \\
\text { the primary tumour } \\
\text { (excluding reconstruction) }\end{array}$ & $\begin{array}{c}\text { Minimum standard: } 80 \% \\
\text { Target: } 90 \%\end{array}$ & $\begin{array}{c}1088 / 1197 \\
(90.9 \%)\end{array}$ & $\begin{array}{l}266 / 296 \\
(89.9 \%)\end{array}$ & $\begin{array}{l}379 / 417 \\
(90.9 \%)\end{array}$ & $\begin{array}{l}443 / 484 \\
(91.5 \%)\end{array}$ & 0.735 \\
\hline $\begin{array}{l}\text { 3. Ql: proportion of patients } \\
\text { with invasive breast cancer } \\
\text { not greater than } 3 \mathrm{~cm} \text { (total } \\
\text { size, including DCIS } \\
\text { component) who } \\
\text { underwent BCT }\end{array}$ & $\begin{array}{c}\text { Minimum standard: } 70 \% \\
\text { Target: } 80 \%\end{array}$ & $\begin{array}{l}669 / 801 \\
(83.5 \%)\end{array}$ & $\begin{array}{l}165 / 211 \\
(78.2 \%)\end{array}$ & $\begin{array}{l}220 / 265 \\
(83.0 \%)\end{array}$ & $\begin{array}{l}284 / 325 \\
(87.4 \%)\end{array}$ & 0.019 \\
\hline $\begin{array}{l}\text { 5. Ql: weight of the excised } \\
\text { specimen from the breast } \\
\text { Mean } \pm \text { S.D. (g) } \\
\text { Proportion of specimens } \\
\text { with weight } \leq 80 \mathrm{~g}(\%)\end{array}$ & $\begin{array}{l}\text { Proportion of specimen } \\
\text { after BCT with weight less } \\
\text { than } 80 \mathrm{~g} \geq 90 \%\end{array}$ & $\begin{array}{l}69.0 \pm 42.5 \\
70.0 \%\end{array}$ & $\begin{array}{l}75.3 \pm 50.3 \\
\quad 61.8 \%\end{array}$ & $\begin{array}{l}63.8 \pm 35.9 \\
75.6 \%\end{array}$ & $\begin{array}{l}69.7 \pm 42.3 \\
70.0 \%\end{array}$ & 0.009 \\
\hline
\end{tabular}

$\mathrm{BCT}=$ breast conserving treatment; $\mathrm{DCIS}=$ ductal carcinoma in situ; $\mathrm{LN}=$ lymph nodes; $\mathrm{QI}=$ quality indicator; S.D.= standard deviation

In 2016, we defined a series of five surgical QIs for therapeutic and two surgical QIs for diagnostic procedures for women diagnosed with breast lesion within national screening program. Overall, the minimal standard was met in two QIs for therapeutic (proportion of patients (invasive and noninvasive cancers) who received a single (breast) operation for the primary tumour (excluding reconstruction) and proportion of patients with invasive breast cancer not greater than $3 \mathrm{~cm}$ (total size, including DCIS component) who underwent BCT) and none for diagnostic procedures. Furthermore, we observed a statistically significant improvement in three QIs for therapeutic (waiting time, proportion of patients with invasive breast cancer not greater than $3 \mathrm{~cm}$ (total size, including DCIS component) who underwent BCT and weight of the excised specimen) and in one QI for diagnostic procedures (waiting time), indicating that regular quality control may improve the quality of sur-

TABLE 3. Results of the diagnostic surgical procedures split by the year of treatment

\begin{tabular}{|c|c|c|c|c|c|}
\hline \multirow{2}{*}{ No. of procedures } & All & 2016 & 2017 & 2018 & \multirow{2}{*}{$\mathrm{p}$-value } \\
\hline & 224 & 78 & 66 & 80 & \\
\hline $\begin{array}{l}\text { Procedure type in axilla: } \\
\text { - none } \\
\text { - SNB } \\
\text { - ALND } \\
\text { - SNB + ALND }\end{array}$ & $\begin{aligned} 208 & (92.9 \%) \\
16 & (7.1 \%) \\
0 & (0.0 \%) \\
0 & (0.0 \%)\end{aligned}$ & $\begin{aligned} 75 & (96.2 \%) \\
3 & (3.8 \%) \\
0 & (0.0 \%) \\
0 & (0.0 \%)\end{aligned}$ & $\begin{array}{l}59(89.4 \%) \\
7(10.6 \%) \\
0(0.0 \%) \\
0(0.0 \%)\end{array}$ & $\begin{aligned} 74 & (92.5 \%) \\
6 & (7.5 \%) \\
0 & (0.0 \%) \\
0 & (0.0 \%)\end{aligned}$ & 0.289 \\
\hline $\begin{array}{l}\text { Histologic tumour type } \\
\text { - Benign } \\
\text { - In situ } \\
\text { - Microinvasive carcinoma } \\
\text { - Invasive carcinoma } \\
\text { - Other malignat }\end{array}$ & $\begin{array}{l}177(79.0 \%) \\
28(12.5 \%) \\
1(0.4 \%) \\
14(6.3 \%) \\
4(1.8 \%)\end{array}$ & $\begin{aligned} 63 & (79.5 \%) \\
11 & (14.1 \%) \\
1 & (1.3 \%) \\
2 & (2.6 \%) \\
1 & (1.3 \%)\end{aligned}$ & $\begin{array}{c}52(78.8 \%) \\
6(9.1 \%) \\
0(0 \%) \\
6(9.1 \%) \\
2(3 \%)\end{array}$ & $\begin{aligned} 62 & (77.5 \%) \\
11 & (13.8 \%) \\
0 & (0.0 \%) \\
6 & (7.5 \%) \\
1 & (1.3 \%)\end{aligned}$ & 0.610 \\
\hline Mean tumour diameter \pm S.D. $(\mathrm{mm})$ & $15.5 \pm 14.1$ & $15.0 \pm 14.1$ & $19.0 \pm 18.7$ & $12.2 \pm 5.7$ & 0.701 \\
\hline
\end{tabular}

ALND = axillary lymph node dissection; S.D. = standard deviation; SNB, sentinel node biopsy 
TABLE 4. Quality indicators of diagnostic surgical procedures split by the year of surgery

\begin{tabular}{|c|c|c|c|c|c|c|}
\hline $\begin{array}{l}1 \text { Ql: waiting time } \\
\text { - Median (days) } \\
\text { - Proportion of patients with waiting time less than } \\
15 \text { working days }\end{array}$ & $\begin{array}{l}\text { Not more than } 15 \\
\text { working days } \geq 90 \%\end{array}$ & $\begin{array}{c}41 \\
10.3 \%\end{array}$ & $\begin{array}{l}44.5 \\
2.6 \%\end{array}$ & $\begin{array}{c}42 \\
6.2 \%\end{array}$ & $\begin{array}{c}34 \\
21.5 \%\end{array}$ & $<0.001$ \\
\hline $\begin{array}{l}2 \text { QI: weight of the excised specimen from the breast } \\
\text { - Mean } \pm \text { S.D. ( } \mathrm{g}) \\
\text { - Proportion of specimens with weight } \leq 30 \mathrm{~g}\end{array}$ & $\begin{array}{l}\text { Proportion of specimen } \\
\text { with weigh less than } \\
30 \mathrm{~g} \geq 90 \%\end{array}$ & $\begin{array}{c}37.3 \pm 23.4 \\
47.8 \%\end{array}$ & $\begin{array}{c}40.3 \pm 25.8 \\
46.2 \%\end{array}$ & $\begin{array}{c}32.6 \pm 22.1 \\
60.6 \%\end{array}$ & $\begin{array}{l}38.2 \pm 22.1 \\
38.8 \%\end{array}$ & 0.131 \\
\hline
\end{tabular}

QI = quality indicator; S.D. = standard deviation

gery. However, the number of QIs meeting the minimum standard was the same through all three studying years.

Timely treatment is an important requisite for the quality of surgery as it maximizes the benefit of early detection and reduces anxiety of patients and their families. ${ }^{5}$ This is especially important in screen-detected lesions as participation rate is critically dependent on patient's satisfaction. Thus, we set a recommendation for waiting time as defined by EBCN (15 working days), which is much stricter compared to EUSOMA (6 weeks). In the first year of our quality control monitoring, only $1.7 \%$ of patients with therapeutic operation and $2.6 \%$ of patients with diagnostic operation met the EBCN recommendations on waiting time for surgery, which is far below the minimum standard $(\geq$ $90 \%$ ). Several reasons contributed to a long wait- ing time. First, our institution has been faced with increasing number of surgical oncology patients and the screening patients had to be scheduled for surgical intervention regarding the waiting time and indications of all patients. Second, during the analysed period our institution was the only hospital in Slovenia performing the surgery of screening patients. Recently another institution, after meeting all necessary quality checks, started to operate on these patients, which will contribute to lower the waiting times. Finally, in many patients longer preoperative preparation including examinations by other physicians (i.e. cardiologist, diabetologist etc.) were required and thus the surgical intervention was postponed until it could be safely performed.

Several measures have been taken to shorten waiting time. First, patients were referred to the

TABLE 5. The variability of QIs within the institution for each studying year and altogether

\begin{tabular}{|c|c|c|c|c|c|}
\hline & & All & 2016 & 2017 & 2018 \\
\hline \multirow{7}{*}{$\begin{array}{l}\text { Therapeutic } \\
\text { procedures }\end{array}$} & $\begin{array}{l}\text { Number of procedures: least active surgeon - most } \\
\text { active surgeon }\end{array}$ & $1-166$ & $1-45$ & $6-62$ & $1-67$ \\
\hline & $\begin{array}{l}\text { Proportion of mastectomies: surgeon with lowest } \\
\text { proportion - surgeon with highest proportion }\end{array}$ & $17.8 \%-100.0 \%$ & $10.0 \%-100.0 \%$ & $12.5 \%-44.4 \%$ & $0.0 \%-100.0 \%$ \\
\hline & $\begin{array}{l}\text { Median waiting time (in days): surgeon with lowest - } \\
\text { surgeon with highest waiting time }\end{array}$ & $28.0-45.0$ & $24.0-45.0$ & $27.0-41.0$ & $23.0-136.0$ \\
\hline & $\begin{array}{l}\text { Single (breast) operation for the primary tumour } \\
\text { (excluding reconstruction): surgeon with lowest - } \\
\text { surgeon with highest proportion }\end{array}$ & $83.1 \%-100.0 \%$ & $73.3 \%-100.0 \%$ & $71.4 \%-100.0 \%$ & $75.0 \%-100.0 \%$ \\
\hline & $\begin{array}{l}\text { Invasive breast cancer not greater than } 3 \mathrm{~cm} \text { who } \\
\text { underwent BCT: surgeon with lowest - surgeon with } \\
\text { highest proportion }\end{array}$ & $0.0 \%-92.6 \%$ & $0.0 \%-94.4 \%$ & $40.0 \%-100.0 \%$ & $77.8 \%-100.0 \%$ \\
\hline & $\begin{array}{l}\text { Weight }(\mathrm{g}) \text { of the excised specimen from the breast: } \\
\text { surgeon with lowest mean - surgeon with highest mean }\end{array}$ & $35.5-89.0$ & $33.5-104.5$ & $28.0-94.0$ & $37.0-81.5$ \\
\hline & $\begin{array}{l}\text { Patients with invasive cancer and axillary clearance } \\
\text { performed with at least } 10 \mathrm{LN} \text { examined: surgeon with } \\
\text { lowest - surgeon with highest proportion }\end{array}$ & $71.4 \%-100.0 \%$ & $50.0 \%-100.0 \%$ & $80.0 \%-100.0 \%$ & $50.0 \%-100.0 \%$ \\
\hline \multirow{3}{*}{$\begin{array}{l}\text { Diagnostic } \\
\text { procedures }\end{array}$} & $\begin{array}{l}\text { Number of procedures: least active surgeon - most } \\
\text { active surgeon }\end{array}$ & $3-30$ & $1-12$ & $1-11$ & $1-12$ \\
\hline & $\begin{array}{l}\text { Median waiting time (in days): surgeon with lowest - } \\
\text { surgeon with highest waiting time }\end{array}$ & $25.5-45.0$ & $24.0-59.0$ & $28.5-76.0$ & $20.0-71.0$ \\
\hline & $\begin{array}{l}\text { Weight }(\mathrm{g}) \text { of the excised specimen from the breast: } \\
\text { surgeon with lowest mean - surgeon with highest mean }\end{array}$ & 18.0-70.0 & $22.0-73.0$ & $15.0-55.0$ & 18.0-94.0 \\
\hline
\end{tabular}

$\mathrm{BCT}=$ breast conserving treatment; $\mathrm{LN}=$ lymph nodes 
surgeon in maximum 2 weeks after the decision on operation was made within multidisciplinary meeting. Second, all other investigations needed before surgery were made on the day of appointment with surgeon. Finally, we provided additional time in operating theatre dedicated for women from screening program. Because of described measures, the waiting time had significantly improved over the next two years. Nevertheless, activities to shorten waiting time should be intensified to reach the minimum standard.

Three QIs from EUSOMA working group had been chosen to monitor the quality of surgery in women with proven breast cancer: proportion of patients (invasive and noninvasive cancers) who received a single (breast) operation for the primary tumour (excluding reconstruction), proportion of patients with invasive breast cancer not greater than $3 \mathrm{~cm}$ (total size, including DCIS component) who underwent $\mathrm{BCT}$ and proportion of patients with invasive cancer and axillary clearance performed with at least $10 \mathrm{LN}$ examined. The recommended standard was met for the first two QIs every single year. Furthermore, QI proportion of patients with invasive breast cancer not greater than $3 \mathrm{~cm}$ (total size, including DCIS component) who underwent BCT significantly improved over the study period. On the other hand, we had not reached the minimal proportion of patients with invasive cancer and axillary clearance performed with at least 10 LN examined. However, in the majority of patients low number of examined lymph nodes was not the result of low technical skills of the surgeons, but rather the decision of the surgeons that complete axillary lymph node dissection might not be necessary, following the trends towards minimizing the axillary surgery as reviewed in an article by Henke et al...5 Overall, the number of these patients is very low. As more data become available that less aggressive axillary surgery does not affect survival in breast cancer patients, the inclusion of this QI in monitoring surgical quality control should be reconsidered. Indeed, in the last version of EUSOMA QIs from 2017, this QI is no longer included and was replaced by QI monitoring the ability to avoid axillary overtreatment (proportion of patients with no more than 5 SLN excised). ${ }^{5}$

As the breast is aesthetically sensitive organ and important for woman's self-esteem, the cosmetic results are of utmost importance in breast surgery. However, measurement of cosmetic results are difficult and subjective assessments could not be ruled out. Weight of the excised specimen is a proxy for expected final cosmetic result and preserved shape and symmetry with the contralateral breast. ${ }^{16}$ Although far from ideal as it does not take into account the effect of oncoplastic reconstruction, it represents an objective measurement of the surgeon's ability to balance between aggressiveness and clear margins on the one hand and cosmetic issues on the other. The weight of the specimen was significantly reduced in the second and third studying year compared to the first one for therapeutic procedures and a trend towards weight reduction was observed for diagnostic procedures. However, the goal was still not met and efforts to reduce the weight of the specimens should be continued.

Besides monitoring surgical QIs at the institutional level, we also analysed the variability of management among surgeons. As all surgeons were informed about their own results each year, we would expect that the variability among surgeons becomes less pronounced over time. However, the variability remained high throughout the studying years, which is most probably the reflection of the number of surgeons involved in breast surgery at our department. As recommended by EUSOMA, any breast surgeon at the breast centre must carry out primary surgery as first operator on at least 50 newly diagnosed breast cancers a year. If the centre has surgeons in training, those responsible for supervising trainees might perform fewer than 50 primary cases as first operator. In this case documentation on their role as second operator supervising trainees must be available. ${ }^{17}$ Although surgeons involved in breast surgery at our department operate other breast lesions besides those detected in the screening program, many surgeons still do not meet the requested volume standards. To further improve the compliance with QIs and to reduce the variability of surgical management inside the institution, the importance of concentrating the breast pathology to a reduced number of surgeons meeting the requested standards could not be overemphasized. It seems that this measure may provide important step towards improved quality of breast surgery.

Although many studies addressed the compliance to QIs as defined by EUSOMA, our study is the first considering only screen-detected breast lesions and including both, diagnostic and therapeutic procedures. Since women with screen-detected lesions represent a specific population and the quality of management of those women, including the quality of surgery, is important not only for the woman in question but also for the appropriate participation rate and the operation of the screening program as a whole, we included QIs specifi- 
cally recommended for screen-detected lesions as well. As a result, our results are not fully comparable to other studies considering EUSOMA QIs only. Nevertheless, the results from other studies show, similar to ours, that complete adherence to guidelines is difficult to achieve. However, continuous monitoring is of paramount importance as it results in better performance of QIs over time. ${ }^{18-20}$

Besides being the first study addressing the topic of monitoring surgical QIs within breast cancer screening program, other strengths of our study are large number of included cases, comprehensive data collection from a prospective database and thus low number of missing data and the recent nature of the data. Furthermore, in the study period all patients with screen-detected lesions detected in the national screening program, underwent surgery at our institution, minimizing the selection bias. The limitations of our study are limited number of QIs that were monitored and inclusion of old EUSOMA QIs defined in 2010. Looking ahead, a set of our QIs should be updated according to the latest EUSOMA recommendations. Furthermore, all potential cofounders were not taken into account in our analysis. First, the results of most EUSOMA indicators improves over time independent of quality control as demonstrated by van Dam et al. ${ }^{18}$; these time trends were not considered in our study. Second, without multivariate analysis adjusting for differences in case mix firm conclusions are difficult to draw. In conclusion, our results showed that adherence to all surgical QIs in patients from screening program is difficult to achieve, especially to those specifically defined for screen-detected lesions. Nevertheless, regular quality control may improve results over time. Reducing the number of surgeons dedicated to breast pathology may reduce variability of management inside the institution.

\section{Acknowledgment}

The study was supported by the research program of the Slovenian research agency P3-0352.

\section{References}

1. Ferlay J, Colombet M, Soerjomataram I, Dyba T, Randi G, Bettio M, et al. Cancer incidence and mortality patterns in Europe: estimates for 40 countries and 25 major cancers in 2018. Eur J Cancer 2018; 103: 356-87. doi: 10.1016/j.ejca.2018.07.005

2. Wang F, Shu X, Meszoely I, Pal T, Mayer IA, Yu Z, et al. Overall mortality after diagnosis of breast cancer in men vs women. JAMA Oncol 2019. [Epub ahead of print]. doi: 10.1001/jamaoncol.2019.2803
3. Lauby-Secretan B, Scoccianti C, Loomis D, Benbrahim-Tallaa L, Bouvard V, Bianchini $F$, et al. Breast-cancer screening-viewpoint of the IARC working group. N Engl J Med 2015; 372: 2353-8. doi: 10.1056/NEJMsr1504363

4. Myers ER, Moorman P, Gierisch JM, Havrilesky $\sqcup$, Grimm L, Ghate S, et al. Benefits and harms of breast cancer screening: a systematic review. JAMA - $J$ Am Med Assoc 2015; 314: 1615-34. doi: 10.1001/jama.2015.13183

5. Biganzoli L, Marotti L, Hart CD, Cataliotti L, Cutuli B, Kühn T, et al. Quality indicators in breast cancer care: an update from the EUSOMA working group. Eur J Cancer 2017; 86: 59-81. doi: 10.1016/j.ejca.2017.08.017

6. Rosselli Del Turco M, Ponti A, Bick U, Biganzoli L, Cserni G, Cutuli B, et al. Quality indicators in breast cancer care. Eur J Cancer 2010; 46: 2344-56. doi: 10.1016/j.ejca.2010.06.119

7. Perry $N$, Broeders $M$, de Wolf $C$, Tornberg $S$, Holland R, von Karsa L European guidelines for quality assurance in breast cancer screening and diagnosis [Internet]. Eur Guidel 2006 [cited 2020 Mar 30]. Available from: http://screening.iarc.fr/doc/ND7306954ENC_002.pdf

8. DORA programme colleagues. [Annual Report on the DORA Breast Cancer National Screening Program 2018]. [Slovenian]. [Internet]. Institute of Oncology Ljubljana - DORA National Breast Cancer Screening Programme 2019 [cited 2020 Mar 30]. Available from: https://dora.onko-i.si/fileadmin/ user_upload/Dokumenti/DORA_letno_porocilo_2018 knjiznica.pdf

9. Cicero U, Rietjens M, Mahmoud ET, Virgilio S. Oncoplastic and reconstructive breast surgery. Cham: Springer; 2019.

10. Rizzo M, Bumpers H, Okoli J, Senior-Crosby D, O'Regan R, Zelnak A, et al. Improving on national quality indicators of breast cancer care in a large public hospital as a means to decrease disparities for african american women. Ann Surg Oncol 2011; 18: 34-9. doi: 10.1245/s10434-010-1204-z

11. Wilcox N, McNeil JJ. Clinical quality registries have the potential to drive improvements in the appropriateness of care. Med J Aust 2016; 205: S27-9. doi: $10.5694 / \mathrm{mja} 15.00921$

12. Cheng SH, Wang CJ, Lin JL, Horng CF, Lu MC, Asch SM, et al. Adherence to quality indicators and survival in patients with breast cancer. Med Care 2009; 47: 217-25. doi: 10.1097/MLR.0b013e3181893c4a.

13. Van Dam PA, Verheyden G, Sugihara A, Trinh XB, Van Der Mussele H, Wuyts $\mathrm{H}$, et al. A dynamic clinical pathway for the treatment of patients with early breast cancer is a tool for better cancer care: implementation and prospective analysis between 2002-2010. World J Surg Oncol 2013; 11: 70. doi: 10.1186/1477-7819-11-70

14. Plavc $G$, Ratoša I, Žagar T, Zadnik V. Explaining variation in quality of breast cancer care and its impact: a nationwide population-based study from Slovenia. Breast Cancer Res Treat 2019; 175: 585-94. doi: 10.1007/s10549019-05186-z

15. Henke G, Knauer M, Ribi K, Hayoz S, Gerard MA. Tailored axillary surgery with or without axillary lymph node dissection followed by radiotherapy in patients with clinically node-positive breast cancer (TAXIS): study protocol for a multicenter, randomized phase-III trial. Trials 2018; 19: 667. doi: 10.1186/s13063-018-3021-9

16. Ojala K, Meretoja TJ, Leidenius MHK. Aesthetic and functional outcome after breast conserving surgery - Comparison between conventional and oncoplastic resection. Eur J Surg Oncol 2017; 43: 658-64. doi:10.1016/j. ejso.2016.11.019

17. Biganzoli L, Cardoso F, Beishon M, Cameron D, Cataliotti L, Coles CE, et al. The requirements of a specialist breast centre. Breast 2020; 51: 65-84. doi: 10.1016/j.breast.2020.02.003

18. Van Dam PA, Tomatis M, Marotti L, Heil J, Mansel RE, Rosselli del Turco $\mathrm{M}$, et al. Time trends (2006-2015) of quality indicators in EUSOMAcertified breast centres. Eur J Cancer 2017; 85: 15-22. doi: 10.1016/j. ejca.2017.07.040

19. Van Dam PA, Tomatis M, Marotti L, Heil J, Wilson R, Rosselli Del Turco M, et al. The effect of EUSOMA certification on quality of breast cancer care. Eur J Surg Oncol 2015; 41: 1423-9. doi: 10.1016/j.ejso.2015.06.006

20. Hartmann-Johnsen OJ, Kåresen R, Schlichting E, Naume B, Nygård JF. Using clinical cancer registry data for estimation of quality indicators: Results from the Norwegian breast cancer registry. Int J Med Inform 2019; 125: 102-9. doi: 10.1016/j.jijmedinf.2019.03.004 